\title{
Content Analysis of Award Winning Television Advertisements: Implications for Advertising Creativity in Pakistan
}

\author{
Amina Haider ${ }^{1}$ \\ Wisal Ahmad ${ }^{2}$ \\ Usman Ghani ${ }^{3}$
}

\begin{abstract}
The advertising professionals and agencies are always doing their level best to develop eye-catching and heart touching creative advertisements so that companies get sufficient return on their advertising expenditures. Moreover, advertising researchers have consensus on the conceptualization of advertising creativity and ascertain that creative advertisements are both novel and meaningful. However, which of the advertising elements such as advertising jingles, slogan, character, storyline and advertising drama contribute to advertising creativity is one of the recent issues that has been least studied. The aim of this study is to investigate how these advertising elements contribute towards enhancing the advertising novelty and meaningfulness, the two foremost dimensions of advertising creativity. Towards this end, forty-one award-winning television advertisements are reassessed for creativity (study one) and subsequently, eleven ads are content analyzed (study two) for its role in enhancing advertising novelty and advertising meaningfulness. The mean analysis of novelty and meaningfulness for the respective advertising elements provide evidence that advertising slogan and dramatization had a significant impact in enhancing advertising creativity. It is also paramount to mention that other advertising elements including jingles, character and storyline though did not attain significance, however, also reflected sufficient agreement for its contribution to ad novelty and meaningfulness. The study findings present valuable implications for business and advertising professionals in Pakistan.
\end{abstract}

JEL Classification: $M 3, M 37, M 39$

Keywords: Creative Advertisement, Creativity, Novelty, Meaningfulness

\section{INTRODUCTION}

The production and creation of creative advertisementshave long been a concern for both the advertising agencies and advertisers. Advertising has got a fundamental position in the organizations and for the same reason, the creativity of advertisements is considered very important for the success of advertisement as well as the advertising agencies developing such ads (Ang \& Low, 2000). Designing creative ads is assumed to be the most fundamental task of an agency since it affects the client of ad-agencies (Tellis, 1997). With an increasing number of products entering the market, the competition gets more intensified. But just producing a good product is usually not considered sufficient to contest particularly in a highly competitive market (Alsmadi, 2006; Kumar \& Reinartz, 2006). Consumers are increasingly becoming highly sophisticated, educated, choosy, and savvier in their buying decisions. Further with so many substitute consumer goods flowing into the market providing more or less the same functions, the only tool used to differentiate them is through the use of creative advertisements. Thus, advertisers and marketers realize the vital role of creativity in making advertisements as they believe that creative advertisements are comparatively more effective

1\&2 - Institute of Business Studies, Kohat University of Science and Technology. Email: wisalkust@hotmail.com 3- Institute of Management Sciences, Peshawar.

\begin{tabular}{llll}
\hline JISR-MSSE & Volume 17 & Number 1 & Januay-June 2019 \\
\hline
\end{tabular}


in capturing viewers' attention that will really put the brand in their mind for a fairly good span of time. For this reason, nowadays most of the companies strive hard to make their advertisement campaigns more unique, successful and striking (Barry, 2012).

In Pakistan, the advertising industry is flourishing over time. Initially, the local businesses were mostly utilizing the available medium that was commonly magazines, newspapers and digests. As the new businesses began to grow and expand, the competing efforts turned more intensified. The new players entering into the market realized the fact that to stay alive and to gaina competitive edge, the industry thus needs to be more creative and professional for it (Ahmad \& Mahmood, 2011). Television is the medium of choice, and in Pakistan, the television enjoys a high attractiveness that is almost matchless by any other medium in the country. This particular medium breaks through the barriers of literacy and reaches out to the masses irrespective of education level and therefore enjoys probably a more heterogeneous audience.

Notably, earlier research on advertising creativity has either looked into the effectiveness of creative ads (Marthak, 2013; Shirkhodaee \& Rezaee, 2014, Till \& Baack, 2005) or mere conceptualization of advertising creativity (Ang, Leong \& Lee, 2007). For instance, Kover, Goldberg and James (1995) found that creative advertisements are more liked and recallable. While investigating the persuasiveness of creative advertising, Ang and Low (2000) found that creative advertisements are significantly more persuasive than normal advertisements. Shirkhodaee and Rezaee (2014) argue on the effective influence of creative advertising on brand attitude, ad. credibility, ad attitude, and the purchase intention. Similarly, towards the conceptualization of creative advertisements, Ang et al. (2007) conceptualized creative advertisements as those which are novel and meaningful. More recent research on advertising creativity has even explored the creative process which makes an advertisement most or least creative (Ahmad, Stufhault \& Labianca, 2017). The extant literature on advertising creativity however surprisingly evidences that though researchers have started taking interest in this complex phenomenon, there is the least amount of research addressing the relative significance of various advertising elements towards advertising creativity (Ahmad, Stufhault \& Johnson, 2016). More explicitly, the current researchers even on the content analysis ofaward-winning advertisements have looked into the suitability of western advertising standards in the local Asian culture such as India (Dixit, 2005) and China (Dongjin, Shenghui \& Hua, 2007). Other advertising content analysis studies have used content analysis as a methodological approach for studying various advertising phenomenon such as content analysis for children representations in ads (Zantides \& Zapiti, 2011), content analysis of women as a tool in ads (Valls-Fernández \& Martínez-Vicente, 2007), gender stereotyping (Nassif \& Gunter, 2008) and many others have looked into other aspects of advertisements using content analysis as a methodology. The extant research on advertising creativity particularly from a creative process perspective as well as the relative effectiveness of creative advertisements is no doubt important; however, the question "what makes an advertisement more creative" is yet to be addressed (Shirkhodaee \& Rezaee; 2014; Ahmad, Stufhault \& Labianca, 2017). This research aims to bridge this gap by exploring the role of various contents of the award-winning creative advertisements in making the respective advertisements more creative. While adopting the generally agreed conceptualization of advertising creativity, the study looks into the role of various contents of advertisements such as advertising character, slogan, jingles, storyline and dramatization in making the ad more novel and meaningful and hence more creative.

110 January-June $2019 \quad$ Volume $17 \quad$ Number 12 JISR-MSSE


It is also pertinent to mention that earlier researchers have consistently used award-winning advertisements as creative advertisements (Kover, 1995; Ang, et al., 2007; Ang \& Low, 2000; Till \& Baack, 2005). However, advertising researchers are also of the view that award-winning ads being assessed by advertising professionals not only suffer from professional biases but also professionals assess creativity different than final consumers (Amabile, 1996; Till \& Baack, 2005; Ahmad \& Mahmood, 2011). We believe that for sufficient validity of the research, the award-winning ads being assessed for creativity by professionals should be further subject to final consumers' assessment so that more robust measure of advertising creativity could be obtained. Hence, doing so will also ensure that advertising creativity should be such which is deemed acceptable to the final consumer. Hence, unlike earlier research, this study adopts a more robust approach towards assessing the role of various contents of creative advertisements such that award-winning creative ads being assessed creative by advertising professionals are reassessed for creativity using established conceptualization of advertising creativity. Despite contributing to advertising creativity literature, the study findings will considerably enrich our understanding of how television advertisements in Pakistan can be made more creative by understanding the role of its several elements towards creativity.

\section{Significance Of The Study}

As earlier stated, the study contributes to the body of knowledge on advertising creativity as well as offer insights for advertising professionals. There is a lack of understandingof the role of various advertising contents in enhancing the advertising creativity (Ahmad, Stufhault \& Labianca, 2017; Shirkhodaee \& Rezaee; 2014). Earlier studies on advertising creativity have either conceptualized creativity in advertising (e.g., Ang et al., 2007; Ang \& Low, 2000) or effectiveness of advertising creativity (Till \& Baack, 2005; Ahmad \& Mahmood, 2011) and the creative process which leads to creative outcome (Ahmad et al., 2017). However, least amount of research exists on the role of advertising elements (e.g., advertising character, slogan, jingles, storyline etc) in enhancing advertising creativity (Shirkhodaee \& Rezaee, 2014; Ahmad et al., 2017). Even the extant research on award-winning creative advertisements have least addressed the role of various advertising elements in making an advertisement more or less creative (Zantides \& Zapiti, 2011; Nassif \& Gunter, 2008). Hence, the current investigation content analyzes the award-winning advertisements in Pakistan to determine the role of each content of these ads (e.g., Slogan, Jingles etc) in enhancing the creativity of advertisements. More explicitly, the study will add to existing advertising creativity literature by revealing the role of each advertising elements towards advertising novelty and meaningfulness, being the dimensions of advertising creativity. Besides, the study findings will also provide useful insights to advertising professionals which will help the advertising agencies in developing more creative advertisements in Pakistan.

\section{LITERATURE REVIEW}

The significance of creativity in advertising is widely recognized, both among academicians and practitioners (Ahmad \& Mahmood, 2011). Advertising professionals believe that creativity in advertising helps to break through greater media clutter (e.g. Ang et al., 2007; Pieters, Warlop \& Wedel, 2002). Consequently, marketers are now shifting towards demanding creative advertisements for their advertising campaign (Ang et. al., 2007). As such, creative advertisements are believed to reach to consumer's minds, build a positive impression and lead to greater persuasiveness of the advertising campaign (Ang et al., 2007). Besides

\begin{tabular}{llll}
\hline JISR-MSSE & Volume 17 & Number 1 & January-June 2019 \\
1111
\end{tabular} 
greater effectiveness of creative advertisements, these are also used as a barometer of advertising excellence (Ahmad \& Mahmood, 2011) and as a result of each year numerous nominations are submitted for creativity awards. The winning of creative awards is a feeling of proud for advertising agencies and the recognition of advertising creative work (Ahmad \& Mahmood, 2011). Hence, creativity is essentially believed to be a necessary tool in advertising especially in today's time when there is intensive media clutter and the companies demand more novel and creative ads in order to effectively differentiate their brands.

Creativity in advertising has been defined in several ways. Smith and Yang (2004) believe that creativity ads are supposed to be the most relevant and divergent. Marra (1990) describes creative advertising as being relevant, novel and fresh ideas. Taylor, Hoy, and Haley (1996) state that the advertising creativity definitions vary across different cultures, but certain vital factorsseem to be common such as novelty and meaningfulness. Wilken (2001) while summarizing all available range of definitions concludes that creativity comprises the creation of fresh ideas or the recombination of certain features to bring out something novel, bringing out valuable solutions to a problem. All of these definitions either directly or indirectly confirm novelty and meaningfulness in advertisements as the dimensions of creativity (Ang et al., 2007). Sternberg and Lubart (1996) argue that creativity is the capability to produce work that is considered both novel and meaningful. Amabile (1996) believes that a response will be described as creative to the scope of its novelty and meaningfulness. Thus, a creative outcome in advertising literature is consistently believed to be as anything which is novel and meaningful (Sternberg \& Lubart, 1996; Amabile, 1996).

Literature on advertising creativity confirms that at least one of the factor of creativity must be "novelty" (also called as divergence," "originality," "Newness," and "un expectancy,") (Ang \& Low, 2000; El Murad \& West, 2004; Sternburg \& Lubart, 1996; Haberland \& Dacin, 1992; Sasser \& Koslow, 2012). Lehnert et al. (2014) believe that in order to be creative, the advertisement must divert from the established norm. The basic theme is in the notion that no one else thought of it earlier. Novelty is how differently an ad is being executed in contrast to other ads in the same category (Ang \& Low, 2000; Sheinin, Varki \& Ashley, 2011). Thus, novelty is the key factor that needs to be given utmost importance when determining about a product's creativeness, irrespective of another likely criterion (Jackson \& Messick, 1965; White \& Smith, 2001). However, researchers are also of the view that creativity no doubt how novel may it be unless it is purposeful and meaningful, cannot be termed as creative. Meaningfulness generally portrays goal orientation and relevancy. Consumer perspective depicts that ads should be valued by the audience in some way. Meaningfulness comprises that the elements of an ad must be considered relevant to the message being conveyed (Ang \& Low, 2000). They are actually depicting how information in an ad devotes to or diverge the target audience from the ad message. Lehnert et al. (2014) argue that the ultimate goal of meaningfulness is to create some way of connecting with the target audience. It is pertinent to mention that earlier research has consistently used novelty and meaningfulness as the two criteria for advertising creativity (Ang et al., 2007).

\section{Content Analysis of Television Advertisements}

Content analysis is a research technique which is used to make valid and replicable inferences from texts to the contexts of their use. In advertising research studies, content analysis can be applied to find out the existence of certain themes, execution elements (i.e. texts, ad copy background, character), and to quantify this presence in an objective manner (Harun, Teo,

112 January-June $2019 \quad$ Volume $17 \quad$ Number $1 \quad$ JISR-MSSE


Hussin \& Nasir, 2014). Ang and Low (2000) state four key functions of content analysis: to approve what is already assumed; to rectify the 'optical illusions' of specialists; to resolve differences among specialists and to develop and test hypotheses. Quantitative content analysis provides the exact count of the frequencies of certain selected elements from an advertisement. This technique helps the researcher to shrink large sets of data into a form which is easily manageable and is, therefore, able to characterize the data variation with summary statistics such as percentages, ranges and averages. This study aims to ascertain the role of different advertising contents (e.g., ad slogan, jingles, character etc) towards enhancing the advertising creativity in terms of advertising novelty and meaningfulness. Hence, the predominant approach employed in this study is a content analysis of television advertisements.

The advertisement elements include the content about which the information will be gathered from television advertisements. Advertising researchers have investigated various categories of advertising contents such as visual devices, auditory devices, advertising appeal, music and dancing (Dixit, 2005). However as earlier mentioned, content analysis of award-winning advertisement has been least studied (Dixit, 2005; Ahmad et al., 2017). Much of the literature on content analysis has looked into it from methodological perspective such that some researchers while content analyzing the ads investigated the children representations in ads (Zantides \& Zapiti, 2011), others have studied how women have been portrayed in advertisements (Valls-Fernández \& Martínez-Vicente, 2007), gender stereotyping (Nassif \& Gunter, 2008) and many others have looked into other aspects of advertisements. The general content analysis of award-winning ads has mainly looked into five common dimensions. These are jingle, slogan, character, storyline and dramatization. Though there are different categorizations of each element in the literature as examined in the study of Dixit (2005), however, these five elements form the major component of television advertisement (Ang et al., 2007).

Drama in television advertising can be used as a tool to generate awareness among masses. Drama is believed to be an essential element of a television advertisement because out of all forms of art, only drama can communicate a tremendous amount of information on a lot of levels instantaneously just within the span of a few seconds (Esslin, 1979). Brecht (1977) the great theoretician was the first one to raise the need for drama to be "quotable" and to deliver the message by gestures, phrases and images that are easily remembered and reproduced. According to Kivinen and Vanyushyn (2014), consumers usually give greater preference to advertising that contains an advertising message in a dramatic way. They further argue that it motivates and move people's minds and emotions. In fact, the drama execution style has an inherent inspiring story that leads to greater persuasiveness. De Mooij (1998) believes that drama is used to indirectly present the product benefits rather a straight direct communication about the product benefits. This, in fact, increases the memorability of advertising information and consumers can later recall the advertising drama (Kivinen \& Vanyushyn, 2014).

Storytelling is one of the ways using which markets can present action in a television commercial more intensely than in any other media. A good story thus creates an emotional connection between the product and consumer and also communicates to the consumer (Fog, Budtz \& Munch, 2009). In storytelling, images are combined with the words to present a creative concept and a story. Aristotle's describes that a story is a chain of actions or events rendered in an entity having a beginning, middle, and an end (Ang \& Low, 2000). The events

\begin{tabular}{llll}
\hline JISR-MSSE & Volume 17 & Number 1 & January-June 2019 \\
\hline
\end{tabular}


of a story, which are usually temporally and causally connected, are selected on the basis of how well the core point of the story is represented (Ang \& Low, 2000). As in the drama execution style, Kivinen and Vanyushyn (2014) found that consumers remember advertisements that have a touching and interesting storyline. Um (2013) believe that storyline is particularly more effective in those advertisements in which the advertising character is a non-celebrity since the celebrity advertisements are itself more memorable. Almost similar views are reflected by De Mooij (1998) who ascertains that storyline is more appropriate in indirect advertisements in which the advertising message is usually communicated through a drama. He further believes that storyline connects the target audience with the product being promoted in the advertisement. In fact, the storyline covers the advertising message in a comprehensive way and concludes the entire advertising (Um, 2013).

In a television advertisement, a story needs a certain character to interact with each other and that the audience can correlate themselves with. Advertising character can be a spokesperson who shares his / her experiences with the product, a celebrity endorses who is believed to be the expert in his field as well as an ordinary man (Ang et al., 2007). That's why, the characters being used in the advertisement should be very attractive (Asemah, Edegoh \& Ogwo, 2013). The reason being that consumers who actually see the advertisement will believe the persona of the brand as well as the associated with the particular character being shown in the advertisement. Research on the effectiveness of character in making the brand more memorable is somehow debatable (Ang et al., 2007). Some researchers reflect that if the endorses of the brand are highly renowned and attractive, people remember the personality or character and ignore the brand. It is however believed that there should be a match between the product and the character in order to be effective (Um, 2013).

It is also believed that some of the companies and products are successful not because they have a pool of satisfied customers, but because customers were keen on a specific jingle in an advertisement. A jingle is an appealing phrase of words with a mesmerizing tune or simply it is just a short repetitive song. In a TV commercial, jingle not only affects consumers subconsciously but also greatly influence how we see the product that is being advertised and the advertisement in general. An attractive jingle not only attains the attention of customer but makes him (or her) think twice about a product; a bad jingle might distract people from looking at a particular brand. Most of the tv ads use attractive jingles and s catchy-word or phrases (slogan) that yield persistent appeal and stays in consumer mind even long after the span of the advertising campaign (Igbinoba, 2012). Advertising slogans is one of the identity components which play a key role in making brand affect customer's mind (Abdi \& Irandoust, 2013). Hence, besides other features, creative advertisements may also use attractive and catchy jingles.

Besides using such advertising elements, the advertising professionals also use attractive and catchy-word or phrases (slogan) that produces persistent appeal and remain in consumer mind even long after the time span of an advertising campaign (Igbinoba, 2012). Advertising slogans are considered as one of the important components which play the main role in making brand affect customer's mind (Abdi \& Irandoust, 2013). The thoughtful use of advertising slogan is valuable for the firm (Mathur \& Mathur, 1995). Such brand identity elements including slogans have been found to significantly affect consumer brand awareness, a brand image which ultimately builds consumers' brand knowledge and ultimately brand equity (Aaker, 1991). Earlier studies have particularly found a strong relationship between short and

114 January-June $2019 \quad$ Volume $17 \quad$ Number $1 \quad$ JISR-MSSE


catchy slogans and advertising recall compared to complex slogans (Abdi \& Irandoust, 2013). It is also paramount to mention that advertising professionals have stressed the importance of advertising slogan in making an advertisement more novel and creative. In fact, the advertising slogan provides novelty to the brand (Abdi \& Irandoust, 2013). As such, creative advertisements are more likely to possess a short and catchy slogan that grabs consumers' attention.

\section{METHODOLOGY}

\section{Population and Sampling}

The primary objective of this study is to look into the role of each content of creative advertisements towards advertising creativity and so the nature of the research is descriptive. Hence, the population frame used for the study is all the creative Advertisements having won the Pakistan Advertisers Society awards representing for the past two years' i-e 2016 and 2017. The required ads were obtained from the Pakistan Advertisers Society (PAS). This sample includes all the consumers' goods and services television advertisements representing various product categories including Beverages, Food and Diary, Cosmetics and Personal Care, Textile and Fashion, Telecom Service Provider, Confectionary and Snacks, and Ice-cream and Deserts.

\section{Data Collection and Measuring Instrument}

The study was conducted in two phases: the first phase aimed at identifying those PAS advertisements which are though assessed creative by advertising professionals (as they have won advertising creativity awards) are reassessed by final consumers for advertising novelty and meaningfulness. In line with earlier advertising studies (Smith, Chen \& Yang, 2008; Scarrot \& Mc Donald, 2012), a total of forty-one ads were assessed for creativity by six business students using the well-established dimensions of novelty and meaningfulness (Alpert, Alpert \& Maltz, 2005). It is worth mentioning that since the study intended to assess the contents of award-winning creative ads, therefore the sample unit of the study remained award-winning ads not individuals. Further, unlike previous studies (Scarrot \& Mc Donald, 2012) in which only two independent raters assessed the advertising contents, this study used six independent raters to assess the award-winning ads which in fact adds to the study rigour and validity. After watching each of the forty-one ads, subjects responded to the creativity measures.Five-point Likert scale was used to tap consumers' response of the respective advertisements using four items each for advertising novelty and meaningfulness (Haberland \& Dacin, 1992). In line with earlier studies (Scarrot \& Mac Donald, 2012) a threshold level of 3.5 on the scale of 5 was used to determine the novelty and meaningfulness of the respective ads. As a result, eleven ads were finally rated as creative ads.

In the second phase, the eleven creative ads being assessed as creative by final consumers (study one) were content analyzed by the same research subjects with the aim to determine which element of the creative ads (e.g., Ad slogan, character, storyline etc) contribute more towards the novelty and meaningfulness of the respective ads. After watching each of the eleven ads, the subjects rated the contribution of various elements of the creative ads (e.g., Slogan Ad drama etc.) in the novelty and meaningfulness of the respective ads. Same five point Likert scale with four items for novelty and four items for meaningfulness were used 
(Haberland \& Dacin, 1992). As practised in content analysis, the final data was analyzed for descriptive statistics and mean analysis using one sample t-test in order to confirm the role of each element of the respective creative ads towards advertising creativity.

\section{Data Analysis}

This study aimed at understanding how different advertising elements (e.g., Ad Drama, slogan etc) contribute towards enhancing the creativity of an advertisement in terms of novelty and meaningfulness. As stated earlier, the study was conducted in two phases such that in the first phase, the award-winning creative advertisements were reassessed by six business students for creativity using established criteria of novelty and meaningfulness. In the second phase, the ads being assessed creative in the first phase were content analyzed by the same subjects for ascertaining the role of various advertising elements towards advertising ad-novelty and meaningfulness as the two measures of advertising creativity. Hence, the study findings are presented in two folds.

\section{Study 1: Filtration of Creative Ads}

Advertising literature confirms the disagreement in the level of creativity assessment such that advertising professionals are found to over-evaluate advertising creativity compared to researchers and final consumers (Modig, 2012; Smith \& Yang, 2004). Hence, for study one, all the forty-oneaward-winning creative ads nominated by PAS in seven product categories for years 2016 and 2017 were reassessed for advertising novelty and meaningfulness, being the two measures of creativity. Both the novelty and meaningfulness measures were measured using established measure (Ang et al., 2007), each with four items on five point Likert scale for novelty and meaningfulness. In line with earlier studies of advertising (Modig, 2012), a cut-off value of 3.5 (threshold value) on the scale of 5 was used to segregate an advertisement novelty and meaningfulness and hence to decide whether an advertisement is creative or not. Table 1 below shows the mean novelty and meaningfulness for each of theforty-one ads. As a result, out of 42 ads, a total of 11 ads were assessed as more creative with ad-novelty and meaningfulness score above the cut-off point of 3.5 (Scarrot \& Mac Donald, 2012). The selected eleven ads were then content analyzed in study- 2 for assessing the role of its various contents (e.g., Ad slogan, jingles etc) towards advertising novelty and meaningfulness. 
Table 1. Reassessment of Award Winning Television Ads by Final Consumers

\begin{tabular}{|c|c|c|c|c|c|}
\hline Category & $\begin{array}{l}\text { Year } \\
2016\end{array}$ & Advertisement & \begin{tabular}{|c|}
$\begin{array}{c}\text { Grand Mean } \\
\text { Novelty }\end{array}$ \\
\end{tabular} & \begin{tabular}{|c|} 
Grand Mean \\
Meaningfulness \\
\end{tabular} & Selection Status for Study 2 \\
\hline \multirow{6}{*}{ 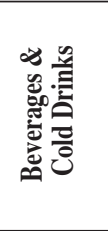 } & 2016 & Pepsi khana banayea exciting & 3.94 & 3.50 & Ad Selected for Study 2 \\
\hline & 2016 & Coca colar music 2015 & 3.34 & 3.06 & Ad Not Selected for Study 2 \\
\hline & 2017 & Sprit Spicy & 3.67 & 3.72 & Ad Selected for Study 2 \\
\hline & 2017 & Fanta hundred & 3.61 & 3.51 & Ad Selected for Study 2 \\
\hline & 2017 & Coca-cola pila dea & 3.45 & 3.52 & Ad Selected for Study 2 \\
\hline & 2017 & Coca cola pila dea & 3.28 & 3.39 & Ad Not Selected for Study 2 \\
\hline \multirow{6}{*}{ 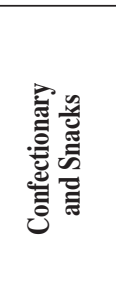 } & 2016 & $\begin{array}{l}\text { Ding Dong Bubble-3D } \\
\text { DD Animated TVC }\end{array}$ & 3.95 & 3.11 & Ad Not Selected for Study ${ }^{2}$ \\
\hline & 2016 & Kolson Snackers- Sharing ka no scene & 3.50 & 3.06 & Ad Not Selected for Study 2 \\
\hline & 2016 & Feshup Illachi & 3.11 & 3.11 & Ad Not Selected for Study 2 \\
\hline & 2017 & Candilan novella-Dil pigal jayea & 3.50 & 3.55 & Ad Selected for Study 2 \\
\hline & 2017 & $\begin{array}{c}\text { Choclate chips cookies- } \\
\text { Bohat Bohat Bohat Choclatee }\end{array}$ & 3.23 & 3.34 & Ad Not Selected for Study 2 \\
\hline & 2017 & Oy huoye - Oy huoye launch campaign & 2.28 & 2.11 & Ad Not Selected for Study 2 \\
\hline \multirow{6}{*}{ 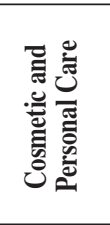 } & 2016 & Lifebuoy-Time before iftar & 3.51 & 3.56 & Ad Selected for Study 2 \\
\hline & 2016 & Sunsilk-Fashion Edition & 3.50 & 3.53 & Ad Selected for Study 2 \\
\hline & 2016 & Garnier-Lose the pimple not your mind & 2.72 & 2.73 & Ad Not Selected for Study 2 \\
\hline & 2017 & Dettol-Dettol ka dulha & 3.51 & 3.78 & Ad Selected for Study 2 \\
\hline & 2017 & Loerel- Don't Stop here & 3.34 & 3.39 & Ad Not Selected for Study 2 \\
\hline & 2017 & LUX - LUX White re-launch & 3.28 & 3.50 & Ad Not Selected for Study 2 \\
\hline \multirow{6}{*}{ 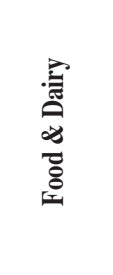 } & 2016 & Dairy Omung- Milawat 2015 & 3.22 & 3.57 & Ad Not Selected for Study 2 \\
\hline & 2016 & Blue Band Margarine- Breadman 2 & 3.17 & 3.06 & Ad Not Selected for Study 2 \\
\hline & 2016 & Taran- Tarangbaz & 3.17 & 2.78 & Ad Not Selected for Study 2 \\
\hline & 2017 & $\begin{array}{c}\text { Nestle Lactogrow 3-Tummy muskuraie } \\
\text { to mamee muskurayee }\end{array}$ & 3.50 & 3.67 & Ad Selected for Study 2 \\
\hline & 2017 & Knor soup- Share the warmth & 3.50 & 3.23 & Ad Not Selected for Study 2 \\
\hline & 2017 & Nurpur- Nurpur cooprporate Thematic & 2.95 & 3.06 & Ad Not Selected for Study 2 \\
\hline \multirow{6}{*}{ 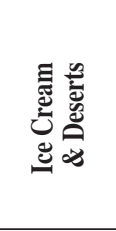 } & 2016 & Omore,Mouj Masti and Maza & 3.67 & 2.89 & Ad Not Selected for Study 2 \\
\hline & 2016 & Omore fun ka endless maza & 3.22 & 2.56 & Ad Not Selected for Study 2 \\
\hline & 2017 & Magnum Release the beast & 3.62 & 3.06 & Ad Not Selected for Study 2 \\
\hline & 2017 & Coneto 2016 & 3.34 & 3.34 & Ad Not Selected for Study 2 \\
\hline & 2017 & Omore Signature campaign & 3.45 & 3.00 & Ad Not Selected for Study 2 \\
\hline & 2017 & Walls Eid mubarik & 3.28 & 3.00 & Ad Not Selected for Study 2 \\
\hline \multirow{6}{*}{ 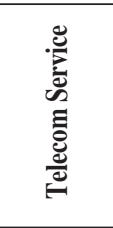 } & 2016 & Ufone- hisab & 4.05 & 3.50 & Ad Selected for Study 2 \\
\hline & 2016 & Mobilink-Call drop & 3.56 & 3.66 & Ad Selected for Study 2 \\
\hline & 2016 & Ufone- Ufone super inami offer & 3.22 & 2.84 & Ad Not Selected for Study 2 \\
\hline & 2017 & Djuice- My Djuice Offer & 3.05 & 3.61 & Ad Not Selected for Study 2 \\
\hline & 2017 & Telenor- Sucha Sath & 3.05 & 3.61 & Ad Not Selected for Study 2 \\
\hline & 2017 & Telenor- Internet Easyload & 2.84 & 3.33 & Ad Not Selected for Study 2 \\
\hline \multirow{6}{*}{ 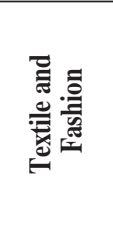 } & 2016 & Borjan Walk the Fashion & 3.45 & 3.33 & Ad Not Selected for Study 2 \\
\hline & 2016 & Service sub kuch naya & 3.34 & 3.12 & Ad Not Selected for Study 2 \\
\hline & 2017 & Service utarnea ka scean hie nahea & 3.39 & 3.17 & Ad Not Selected for Study 2 \\
\hline & 2017 & Borjan Join the Fashion Walk & 3.28 & 3.22 & Ad Not Selected for Study 2 \\
\hline & 2017 & Stylo juo chahoo wo pawoo & 3.11 & 3.06 & Ad Not Selected for Study 2 \\
\hline & 2017 & Stylo where you style through Life & 2.95 & 3.11 & Ad Not Selected for Study 2 \\
\hline
\end{tabular}




\section{Study 2: Content Analysis of Creative Ads}

The purpose of conducting study 2 is to analyze the role of various contents (ad-slogan,jingles etc) of the finally assessed creative ads towards enhancing the novelty and meaningfulness of the respective ads. In line with earlier advertising studies, the same homogenous sample of subjects rated the relative contribution of various advertising elements towards enhancing the novelty and meaningfulness of the respective ads. Same four items on five point Likert scale were used to assess the relative contribution of each of the advertising element. Each of the advertising elements such as advertising slogan, jingles etc were assessed for its contribution towards enhancing the advertising novelty and meaningfulness in total eleven ads. Thus, total five advertising elements in each of the eleven creative ads were examined for novelty and meaningfulness. Mean analysis for each of the advertising element (e.g., ad slogan, jingles etc) in eleven ads was performed which is reflected in table 2 and table 3.

Table 2. Mean Analysis of Advertising Contents Contribution towards Ad Novelty

\begin{tabular}{l|c|c|c|c|c}
\hline Advertisement Description & Ad Jingles & Ad Slogan & Ad Character & Ad Storyline & Ad Drama \\
\hline Pepsi khana banayea exciting & 3.73 & 3.56 & 3.84 & 3.84 & 3.89 \\
\hline Sprit Spicy & 4.17 & 3.78 & 4.11 & 3.84 & 3.78 \\
\hline Fanta hundred & 3.17 & 3.56 & 2.28 & 3.39 & 3.39 \\
\hline Coca Cola music 2015 & 3.78 & 3.73 & 3.45 & 3.39 & 3.62 \\
\hline $\begin{array}{l}\text { Nestle Lactogrow 3-Tummy muskuraie } \\
\text { to mamee muskurayee }\end{array}$ & 3.39 & 3.73 & 3.89 & & \\
\hline Lifebuoy-Time before iftar & 2.50 & 3.56 & 2.78 & 3.45 & 3.56 \\
\hline Sunsilk- Fashion Edition & 3.17 & 3.67 & 3.78 & 3.39 & 3.23 \\
\hline Mobilink-Call drop & 2.89 & 3.39 & 3.62 & 3.62 & 3.62 \\
\hline Candilan novella- Dil pigal jayea & 3.56 & 3.45 & 3.28 & 3.45 & 3.39 \\
\hline Ufone-hisab & 2.84 & 3.62 & 3.89 & 3.84 & 3.73 \\
\hline Dettol-Dettol ka dulha & 3.78 & 3.73 & 3.12 & 3.62 & 3.34 \\
\hline
\end{tabular}

Table 3. Mean Analysis of Advertising Contents Contribution towards Ad Meaningfulness

\begin{tabular}{l|c|c|c|c|c}
\hline Advertisement Description & Ad Jingles & Ad Slogan & Ad Character & Ad Storyline & Ad Drama \\
\hline Pepsi khana banayea exciting & 3.73 & 3.34 & 3.67 & 3.73 & 4.12 \\
\hline Sprit Spicy & 3.73 & 3.78 & 3.56 & 4.17 & 3.84 \\
\hline Fanta hundred & 2.78 & 3.50 & 2.84 & 3.34 & 3.50 \\
\hline $\begin{array}{l}\text { Coca Cola music 2015 } \\
\text { Nestle Lactogrow 3- Tummy muskuraie }\end{array}$ & 3.45 & 3.50 & 3.73 & 3.56 & 3.78 \\
\hline to mamee muskurayee & 3.67 & 3.73 & 3.62 & 3.78 & 3.73 \\
\hline Lifebuoy - Time before iftar & 2.89 & 3.62 & 3.28 & 3.50 & 3.84 \\
\hline Sunsilk- Fashion Edition & 2.95 & 3.50 & 3.45 & 3.89 & 3.62 \\
\hline Mobilink-Call drop & 3.06 & 3.39 & 3.50 & 3.89 & 3.67 \\
\hline Candilan novella- Dil pigal jayea & 3.56 & 3.62 & 3.39 & 3.62 & 3.62 \\
\hline Ufone- hisab & 2.67 & 3.50 & 3.56 & 3.89 & 3.84 \\
\hline Dettol - Dettol ka dulha & 3.39 & 3.73 & 3.12 & 3.78 & 3.62 \\
\hline
\end{tabular}

In order to confirm the role of these different elements in enhancing advertising novelty and meaningfulness, one sample t-test was used based on table 3 and table 2. Again, in line with 
earlier advertising studies (Modig, 2012), a cut-off point of 3.5 was used as a threshold level for confirming the role of an advertising element in the novelty as well as advertising meaningfulness. As shown in table 4 and table 5, the advertising drama and slogan have a significant role in the advertising novelty (Mean Drama-Novelty: 3.67, Mean Slogan-Novelty: 3.62). These means are also significantly above the minimum threshold level of 3.5 . The analysis also reflects that though the other advertising elements did not significantly cross the cut-off point, however, the means are close to the cut-off point and so these elements also play an important role in making an advertisement more novel.

Table 4. One-Sample Statistics: Descriptive Analysis of Advertising Contents Towards Ad-Novelty

\begin{tabular}{l|c|c|c|c}
\hline & $\mathbf{N}$ & Mean & Std. Deviation & Std. Error Mean \\
\hline Role of Jingles in Novelty & 11 & 3.3936 & .53722 & .16198 \\
Role of Character in Novelty & 11 & 3.4691 & .52895 & .15948 \\
Role of Drama in Novelty & 11 & 3.6745 & .25971 & .07830 \\
Role of Slogan in Novelty & 11 & 3.6273 & .14043 & .04234 \\
Role of Story Line in Novelty & 11 & 3.2636 & .36944 & .11139 \\
\hline
\end{tabular}

Table 5. One-Sample Test: Mean Significant Analysis of Advertising Contents Towards Ad-Novelty

\begin{tabular}{l|c|c|c|c|c|c}
\hline \multirow{2}{*}{} & \multicolumn{3}{|c|}{ Test Value = 3.5 } \\
\cline { 3 - 7 } & & & & & \multicolumn{2}{c}{$\begin{array}{c}95 \% \text { Confidence Interval } \\
\text { of the Difference }\end{array}$} \\
\cline { 6 - 8 } & $\mathrm{t}$ & $\mathrm{Df}$ & Sig. (2-tailed) & Mean Difference & Lower & Upper \\
\hline Role of JingRole of Jingles in Novelty & -.657 & 10 & .526 & -.10636 & -.4673 & .2545 \\
Role of Character in Novelty & -.194 & 10 & .850 & -.03091 & -.3863 & .3244 \\
Role of Drama in Novelty & 2.229 & 10 & .050 & .17455 & .0001 & .3490 \\
Role of Slogan in Novelty & 3.006 & 10 & .013 & .12727 & .0329 & .2216 \\
Role of Story Line in Novelty & -2.122 & 10 & .060 & -.23636 & -.4846 & .0118 \\
\hline
\end{tabular}

Table 6 andTable 7 present the descriptive and mean significant analysis of the advertising elements in enhancing the meaningfulness of advertisement. As evident from the table, the same advertising drama and slogan play a significant role in the advertising meaningfulness (Mean Drama-Meaningfulness: 3.74, Mean Slogan-Meaningfulness: 3.66). As found for advertising novelty, the mean values for the role of advertising drama and advertising slogan are significantly higher than the cut-off point. It is also pertinent to mention that research subjects also ratefavourably the other advertising elements for enhancing the advertising meaningfulness. However, it did not attain the significance level. Hence, both the findings of different advertising elements (Ad Jingles, Ad Character, Ad Story Line) for advertising novelty and meaningfulness (Table 4, 5, 6 and 7) which though reach toa substantial agreement among the research subjects but did not reach to the significance can be cautiously interpreted. 
Table 6. One-Sample Statistics: Descriptive Analysis of Advertising Contents Towards Ad-Meaningfulness

\begin{tabular}{l|c|c|c|c}
\hline & N & Mean & Std. Deviation & Std. Error Mean \\
\hline RoRole of Jingles in Ad Meaningfulness & 11 & 3.2618 & .40055 & .12077 \\
Role of Character in Ad Meaningfulness & 11 & 3.4291 & .26289 & .07926 \\
Role of Drama in Ad Meaningfulness & 11 & 3.7436 & .16783 & .05060 \\
Role of Slogan in Ad Meaningfulness & 11 & 3.6691 & .23006 & .06937 \\
Role of Story Line in Ad Meaningfulness & 11 & 3.4218 & .55194 & .16642 \\
\hline
\end{tabular}

Table 7. One-Sample Test: Mean Significant Analysis of Advertising Contents Towards Ad-Meaningfulness

\begin{tabular}{|c|c|c|c|c|c|c|}
\hline & \multicolumn{6}{|c|}{ Test Value $=3.5$} \\
\hline & \multirow[b]{2}{*}{$\mathrm{t}$} & \multirow[b]{2}{*}{ Df } & \multirow[b]{2}{*}{ Sig. (2-tailed) } & \multirow[b]{2}{*}{ Mean Difference } & \multicolumn{2}{|c|}{$\begin{array}{c}95 \% \text { Confidence Interval } \\
\text { of the Difference }\end{array}$} \\
\hline & & & & & Lower & Upper \\
\hline Role of Jingles in Ad Meaningfulness & -1.972 & 10 & .077 & -.23818 & -.5073 & .0309 \\
\hline Role of Character in Ad Meaningfulness & -.895 & 10 & .392 & -.07091 & -.2475 & .1057 \\
\hline Role of Drama in Ad Meaningfulness & 4.815 & 10 & .001 & .24364 & .1309 & .3564 \\
\hline Role of Slogan in Ad Meaningfulness & 2.438 & 10 & .035 & .16909 & .0145 & .3236 \\
\hline Role of Story Line in Ad Meaningfulness & -.470 & 10 & .649 & -.07818 & -.4490 & .2926 \\
\hline
\end{tabular}

The role of these different advertising elements (e.g., jingles, slogan etc) in enhancing advertising novelty as well as advertising meaningfulness is also shown in figure 1 . The figure shows thatbesides the role of other advertising elements, the advertising drama and slogan has a clear role in the advertising creativity.

Figure 1: Novelty and Meaningfulness Mean Analysis of Creative Ad Contents

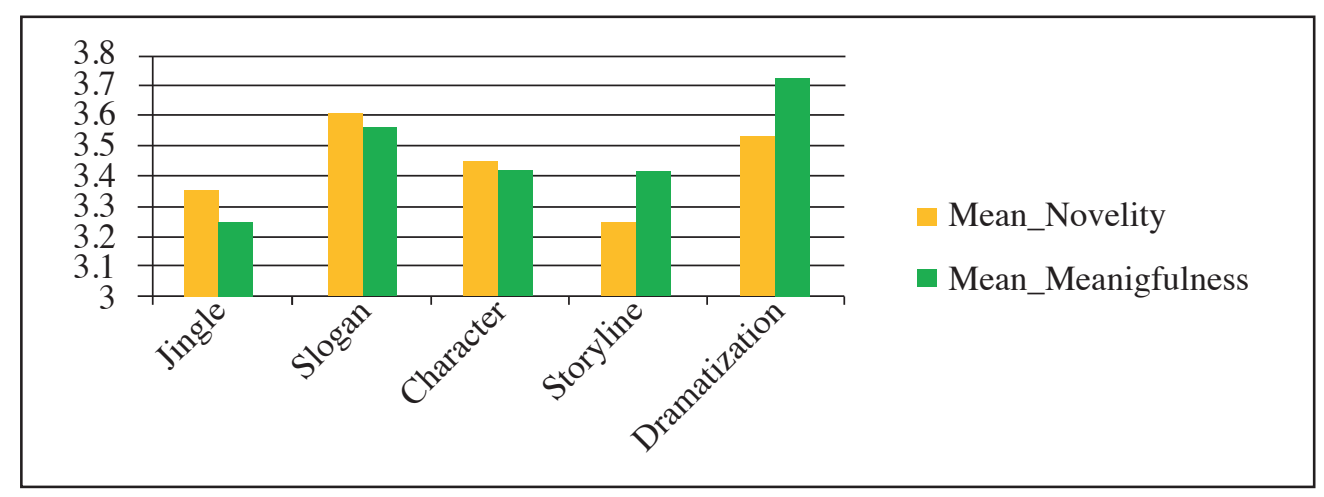

\section{DISCUSSION}

The purpose of this study was to investigate the role of different advertising elements such as advertising slogan, ad character etc in enhancing advertising novelty and meaningfulness; the two measures of advertising creativity. The study reflects the findings in two phases such that creativity award-winning television advertisements were reassessed for creativity by final consumers (study 1) as well as the content analysis of the finally assessed creative ads to 
confirm the role of various advertising elements (jingles, slogan etc) towards enhancing advertising novelty and meaningfulness. As advocated in advertising literature particularly the creativity literature, the consumer's side see things differently particularly the assessment of advertising creativity (Modig, 2012; Smith \& Yang, 2004), therefore the advertisers should fully understand the consumer psychology of how advertisements are assessed by final consumers. The initial findings of this study (study one) substantiate the earlier research which states that professionals assess advertising creativity differently than general people (e.g., Modig, 2012). In study one; the final consumers significantly reduced the number of creative ads (award-winning ads) fromforty-one to only eleven ads which fulfilled the established criteria of ad-novelty and ad-meaningfulness (Ang et al., 2007). Particularly, how the different advertising elements contribute towards advertising creativity should be the focus of creative advertising professionals. Besides the importance of other advertising elements like advertising character, jingle and story line, the significant contribution of advertising slogan and ad drama towards making advertisement more novel and meaningful needs particular attention by advertising professionals while designing advertisements. Hence, it is important that advertising professionals consciously increase their commitment to the production of advertisements which besides other advertising elements significantly focus on creating a novel and meaningful advertising slogan as well as a novel and meaningful advertising drama in order to develop a more creative ad.

The findings of this study also present valuable managerial implications. It is recommended that designing of advertisement in Pakistan must give high priority to these advertising elements including advertising jingles, character, storyline and particularly the advertising slogan and advertising dramatization. These findings evidence that creativity in advertising in Pakistan can be further enhanced by focusing on these ad-elements.

\section{MANAGERIAL IMPLICATIONS}

This study investigated the role of various advertising elements including advertising jingles, slogan, advertising drama and many other elements in enhancing the creativity of television advertisements in Pakistan. The study finds that almost all the elements of advertising have a role in enhancing the advertising novelty and advertising meaningfulness, however, mean significant analysis reveals that advertising dramatization and advertising slogan significantly contribute to both advertising novelty and advertising meaningfulness, being the two measures of advertising creativity. As such, it implies that television advertisements in Pakistan should give more attention to advertising drama and slogan, though other elements such as jingles, advertising character and story line also play its role, however, results for the role of these elements in enhancing advertising novelty and advertising meaningfulness did not attain significance. Thus, in order to develop more creative advertisements in Pakistan, advertising professionals should give particular attention to advertising slogan and advertising drama.

\section{CONCLUSION AND FUTURE RESEARCH}

Creativity is an important factor that can be used for reviving the advertising industry. The consumer's sidealways sees things very differently so the advertisers should fully understand and be focused towards the various contents of an ad in order to help consumers memorize and remember the creative ads than the actual products. The contents of an ad must be creative so 
as to attract and grasp the attention of the customers. The ad agencies must fully concentrate and strive hard on these advertising elements. The result of this study shows that mean novelty and mean meaningfulness values of different contents of the sample advertisements play a substantial role in making the ad creative; however, the advertising slogan and dramatization had a significant impact in enhancing advertising creativity.

Despite the results of this study, the important fact is that creativity in advertising is very much significant for attracting customers' attention. Our study has also revealed the same results reflecting the superior performance of advertising elements particularly advertising slogan and advertising drama in enhancing advertising creativity. It is very much important to mention that the novelty and meaningfulness of all the chosen five ad-contents such as jingle, slogan, character, storyline and dramatization are equally significant. However, among all these five contents, the novelty and meaningfulness of the ad slogan and advertising drama need to be particularly the focus of advertising professionals in Pakistan. The findings of the study will thus help the business professionals and advertising agencies in Pakistan to focus on these advertising contents particularly the advertising slogan and advertising drama while designing television ads.

As with all studies, this study has alsoa few limitations. Although the study used television advertisements for two years representing numerous product and service categories, we believe future studies can further improve the sample size by including advertisements over a wide span of period. Also, due to less representation of many other product categories, the sample was restricted to only consumer goods and service categories. With the increase in product categories over a wide span of time, the results can be further testified. Future researchers can also perform a comparative analysis of content analysis in creative versus non-creative ads in order to more clearly understand the role of these different advertising elements in making an ad more novel and meaningful. It is also suggested that other dimensions of creativity such as advertising humour could be possibly included in other such studies.

\section{REFERENCES}

Aaker, D. A. (1991). Managing Brand Equity: Capitalizing on the Value of a Brand Name. Free Press, New York

Abdi, S., \& Irandoust, A. (2013). The importance of advertising slogans and their proper designing in brand equity. International Journal of Organizational Leadership, 2 (2), 62-69.

Ahmad, W. \& Mahmood, z. (2011). Empirical Investigation of the Association Between Creative Advertising and Advertising Effectiveness, International Journal of Marketing Studies, 4 (2), 133-149.

Ahmad, W., Stufhaut, M., \& Labianca, J. (2017). Collaborative Dynamics of Creative Teams: Modeling Creative Process in Advertising Design, Business and Economics Review, 9(4), 157-180.

Ahmad, W., Stufhaut, M., \& Johnson, N. (2016). Domain Knowledge and Team Creativity: A Typological View, Business and Economics Review, 8(2), 55-66. 
Alpert, M. I., Alpert, J. I., \& Maltz, E. N. (2005). Purchase occasion influence on the role of music in advertising. Journal of Business Research, 58 (3), 369-376.

Alsmadi, S. (2006). The Power of Celebrity Endorsement in Brand Choice Behavior: An Empirical Study of Consumer Attitudes. Journal of Accounting, Business \& Management, 13.

Amabile, T. M. (1996). Creativity in context: Update to the social psychology of creativity. Westview Press.

Ang, S. H., \& Low, S. Y. (2000). Exploring the dimensions of ad creativity. Psychology and Marketing, 17 (10), 835-854.

Ang, S. H., Lee, Y. H., \& Leong, S. M. (2007). The ad creativity cube: Conceptualization and initial validation. Journal of the Academy of Marketing Science, 35 (2), 220-232.

Asemah, E. S., Edegoh, L. O., \& Ogwo, C. A. (2013). Utilization of Aesthetics In Television Advertising. Asian Journal of Social sciences And Humanities, 2, 45-56.

Barry, P. (2012). Advertising Concept Book. Thomson \& Hudson p.55

Brecht (1977). The Sociology of Drama. California: Mayfield Publishing Company.

Dixit, Y. (2005). Indian Award Winning Advertisements: A Content Analysis (Doctoral dissertation, University of Florida).

de Mooij, M. (1998). Global Marketing and Advertising: Understanding Cultural Paradoxes, Thousand Oaks, CA: Sage.

Dongjin, L., Shenghui, A., \& Hua, Y. (2007). A content analysis of the newspaper advertisements westernization in China, Front Bus Res China, 1(4): 558-573.

El-Murad, J., \& West, D. C. (2004). The definition and measurement of creativity: what do we know? Journal of Advertising Research, 44 (2), 188-201.

Esslin, M. (1979). Aristotle and the advertisers: The television commercial considered as a form of drama. The Kenyon Review, 1 (4), 96-108.

Fog, K., Budtz, C., \& Munch, P. (2009). Storytelling: branding i praksis. Samfundslitteratur.

Haberland, G. S., \& Dacin, P. A. (1992). The development of a measure to assess viewers' judgments of the creativity of an advertisement: A preliminary study. ACR North American Advances.

Harun, M.H., Teo, C.B.C., Hussin, F., \& Nasir, S. (2013). The influence of culture in creative strategy and evaluation of international advertising: A content analysis approach. Procedia - Social and Behavioral Sciences, 130 (2013), 419-430.

Igbinoba, O. A. (2012). Drama and Communication in Television Advertising: A Study of MTN's" Sunrise" and Indomie Noodle's" Make the World a Better Place". European Scientific Journal, 8 (5), 67-79.

Jackson, P. W., \& Messick, S. (1965). The person, the product, and the response: Conceptual problems in the assessment of creativity. Journal of personality, 33 (3), 309-329.

Kover, A. J. (1995). Copywriters' Implicit Theories of Communication: An Exploration, Journal of Consumer Research 21: 596-611

Kumar, V., \& Reinartz, W. Customer Relationship Management: A Databased Approach, 2006. John Wiley \& Sons.

Lehnert, K., Till, B. D., \& Ospina, J. M. (2014). Advertising creativity: The role of divergence versus meaningfulness. Journal of advertising, 43 (3), 274-285.

Marra, J. L. (1990). Advertising creativity: Techniques for generating ideas. Prentice Hall.

Mathur, L. K., \& Mathur, I. (1995). The effect of advertising slogan changes on the market values of firms. Journal of Advertising Research, 35 (1), 59-59.

\begin{tabular}{llll}
\hline JISR-MSSE & Volume 17 & Number 1 & January-June 2019 \\
\hline
\end{tabular} 
Marthak, N. (2013), "Creative Advertising and Advertising Effectiveness" Global Research Analysis, 2, 131-135.

Nassif, A., \& Gunter, B. (2008). Gender Representation in Television Advertisements in Britain and Saudi Arabia. Sex Roles, 58, 752-760.

Pieters, R., Warlop, L. \& Wedel, M. (2002). Breaking through the clutter: Benefits of advertisement originality and familiarity for brand attention and memory. Management Science, 48 (6), 765-781.

Sasser, S. L., \& Koslow, S. (2012). Passion, expertise, politics, and support. Journal of Advertising, 41 (3), 5-18.

Scarrott, C., \& MacDonald, A. (2012). A review of extreme value threshold es-timation and uncertainty quantification. REVSTAT-Statistical Journal, 10 (1), 33-60.

Sheinin, D. A., Varki, S., \& Ashley, C. (2011). The differential effect of ad novelty and message usefulness on brand judgments. Journal of Advertising, 40 (3), 5-18.

Shirkhodaee, M., \& Rezaee, S. (2014). The power of creative advertising and consumers' perceived risk. Journal of Promotion Management, 20 (5), 590-606.

Smith, R. E., \& Yang, X. (2004). Toward a general theory of creativity in advertising: Examining the role of divergence. Marketing Theory, 4 (1-2), 31-58.

Smith, R. E., Chen, J., \& Yang, X. (2008). The impact of advertising creativity on the hierarchy of effects. Journal of advertising, 37 (4), 47-62.

Sternberg, R. J., \& Lubart, T. I. (1996). Investing in creativity. American psychologist, 51 (7), 677.

Taylor, R. E., Hoy, M. G., \& Haley, E. (1996). How French advertising professionals develop creative strategy. Journal of Advertising, 25 (1), 1-14.

Tellis, G. J. (1997). Effective frequency: One exposure or three factors? ", Journal of Advertising Research, 37, 75-80.

Till, B. D., \& Baack, D. W. (2005). Recall and persuasion: does creative advertising matter? Journal of Advertising, 34 (3), 47-57.

Valls-Fernández, F., \& Martínez-Vicente, J.M. (2007). Gender Stereotypes in Spanish television Commercials. Sex Roles, 56, 691-699.

White, A., \& Smith, B. L. (2001). Assessing advertising creativity using the creative product semantic scale. Journal of Advertising Research, 41 (6), 27-34.

Wilken, P. C. (2001). Capacity limits for the detection and identification of change: Implications for models of visual short-term memory (Doctoral dissertation, University of Melbourne, Department of Psychology).

Zantides, E., A. Zapiti (2011). Children's Representation in Advertising: A Content Analytic Look, International Journal of Humanities and Social Science (1)2, 45-67. 